\title{
Self-play: statistical significance
}

Article

Accepted Version

Haworth, G. M. (2003) Self-play: statistical significance. ICGA journal, 26 (2). pp. 115-118. ISSN 1389-6911 Available at https://centaur.reading.ac.uk/4549/

It is advisable to refer to the publisher's version if you intend to cite from the work. See Guidance on citing.

Publisher: The International Computer Games Association

All outputs in CentAUR are protected by Intellectual Property Rights law, including copyright law. Copyright and IPR is retained by the creators or other copyright holders. Terms and conditions for use of this material are defined in the End User Agreement.

\section{www.reading.ac.uk/centaur}

\section{CentAUR}

Central Archive at the University of Reading

Reading's research outputs online 


\title{
NOTE
}

\section{SELF-PLAY: STATISTICAL SIGNIFICANCE}

\author{
G. $M^{c}$ C. Haworth ${ }^{1}$
}

Reading, UK

\begin{abstract}
Heinz recently completed a comprehensive experiment in self-play using the FRITZ chess engine to establish the 'decreasing returns' hypothesis with specific levels of statistical confidence. This note revisits the results and recalculates the confidence levels of this and other hypotheses. These appear to be better than Heinz' initial analysis suggests.
\end{abstract}

\section{INTRODUCTION}

Heinz (2000a/b, 2001a/b) reported an extensive self-play experiment with FRITZ to investigate the widely-held belief that an increment of search-depth gives decreasing benefit as depth increases. After a 'White v Black' calibration match between identical players, some seven 'alternating colours' matches were staged in which one player had one ply advantage in fixed iteration depth $p$, although both sides had search extension capability. The experiments included 3,000 games per match, taking the depth $p$ beyond 9 plies to a record 12 plies.

This note offers an analysis of the statistical significance of the results which extends Heinz' own analysis, differs somewhat from it, and provides confidence levels for:

- Heinz' null hypothesis, given the approximating binary win/loss model he adopted,

- Heinz' null hypothesis based on a ternary win/draw/loss model, and

- two subsidiary null hypotheses, on win- and draw-rates, suggested by the data.

Section 2 tables Heinz' results, section 3 establishes the relevant mathematics, and section 4 analyses the experimental results. The summary mentions some open questions that remain.

\section{THE SELF-PLAY EXPERIMENT}

Let $P_{p}$ be a player whose search strategy has a fixed iteration depth parameter of $p$ plies. Let $M_{p}$ be a match between $P_{p}$ and $P_{p-1}$. The one match $M_{p}$ of $n$ games in Heinz' experiment results in an observed score $S_{p o}$ for $P_{p}$ and an observed number - $W_{p o}, D_{p o}$ and $L_{p o}$ - of, respectively, $P_{p}$ wins, draws and losses: $n=3,000$. Table 1 gives this data, and the derived observed $P_{p}$ score, win, draw and loss frequencies, namely $s_{p o}, w_{p o}, d_{p o}$ and $l_{p o}$.

\begin{tabular}{|ccccccccccccc|}
\hline $\boldsymbol{p}$ & $\boldsymbol{M}_{\boldsymbol{p}}$ & $\boldsymbol{W}_{\boldsymbol{p} \boldsymbol{o}}$ & $\boldsymbol{D}_{\boldsymbol{p} \boldsymbol{o}}$ & $\boldsymbol{L}_{\boldsymbol{p o}}$ & $\boldsymbol{S}_{\boldsymbol{p o}}$ & $\boldsymbol{n}$ & $\boldsymbol{w}_{\boldsymbol{p o}}$ & $\boldsymbol{d}_{\boldsymbol{p o}}$ & $\boldsymbol{I}_{\boldsymbol{p o}}$ & $\boldsymbol{s}_{\boldsymbol{p o}}$ & ELO & $\boldsymbol{p}$ \\
$\mathbf{C a l}$ & $\mathrm{M}_{\mathrm{cal}}: \mathrm{P}_{8 \mathrm{~W}}-\mathrm{P}_{8 \mathrm{~B}}$ & 924 & 1,288 & 788 & $1,568.0$ & 3,000 & 0.3080 & 0.4293 & 0.2627 & 0.5227 & & $\mathbf{C a l}$ \\
$\mathbf{6}$ & $\mathrm{M}_{6}: \mathrm{P}_{6}-\mathrm{P}_{5}$ & 1,686 & 915 & 399 & $2,143.5$ & 3,000 & 0.5620 & 0.3050 & 0.1330 & 0.7145 & +159 & $\mathbf{6}$ \\
$\mathbf{7}$ & $\mathrm{M}_{7}: \mathrm{P}_{7}-\mathrm{P}_{6}$ & 1,643 & 1,066 & 291 & $2,176.0$ & 3,000 & 0.5477 & 0.3553 & 0.0970 & 0.7253 & +169 & $\mathbf{7}$ \\
$\mathbf{8}$ & $\mathrm{M}_{8}: \mathrm{P}_{8}-\mathrm{P}_{7}$ & 1,457 & 1,212 & 331 & $2,063.0$ & 3,000 & 0.4857 & 0.4040 & 0.1103 & 0.6877 & +137 & $\mathbf{8}$ \\
$\mathbf{9}$ & $\mathrm{M}_{9}: \mathrm{P}_{9}-\mathrm{P}_{8}$ & 1,433 & 1,235 & 332 & $2,050.5$ & 3,000 & 0.4777 & 0.4117 & 0.1107 & 0.6835 & +134 & $\mathbf{9}$ \\
$\mathbf{1 0}$ & $\mathrm{M}_{10}: \mathrm{P}_{10}-\mathrm{P}_{9}$ & 1,252 & 1,451 & 297 & $1,977.5$ & 3,000 & 0.4173 & 0.4837 & 0.0990 & 0.6592 & +115 & $\mathbf{1 0}$ \\
$\mathbf{1 1}$ & $\mathrm{M}_{11}: \mathrm{P}_{11}-\mathrm{P}_{10}$ & 1,124 & 1,525 & 351 & $1,886.5$ & 3,000 & 0.3747 & 0.5083 & 0.1170 & 0.6288 & +92 & $\mathbf{1 1}$ \\
$\mathbf{1 2}$ & $\mathrm{M}_{12}: \mathrm{P}_{12}-\mathrm{P}_{11}$ & 1,059 & 1,592 & 349 & $1,855.0$ & 3,000 & 0.3530 & 0.5307 & 0.1163 & 0.6183 & +84 & $\mathbf{1 2}$ \\
\hline
\end{tabular}

Table 1: Results of the Heinz self-play experiment.

\footnotetext{
${ }^{1}$ 33, Alexandra Rd., Reading, Berkshire, RG1 5PG, UK. email: guy.haworth@laposte.net
} 


\section{UNDERLYING MATHEMATICS}

Let the corresponding underlying, intrinsic $P_{p}$ score, win, draw and loss frequencies in $M_{p}$ be $s_{p}, w_{p}, d_{p}$ and $l_{p}$ respectively. These are unknown, and are treated as if they were random variables $S_{p}, W_{p}, D_{p}$ and $L_{p}$ whose distributions are to be estimated as well as possible from the observed data. $w_{p}, d_{p}$ and $l_{p}$ are binary variables, while $s_{p}$ is a ternary variable which can be approximated by a binary variable. The experiment was carefully designed to ensure that the matches $M_{p}$ were a sequence of independent Bernoulli trials of these random variables.

Let $B$ be a sequence of $n$ Bernoulli trials of a binary, random variable $X$ with two values $0 / 1: X=1$ with probability $x, X=0$ with probability $1-x$. The following notation and results are standard (Feller, 1968):

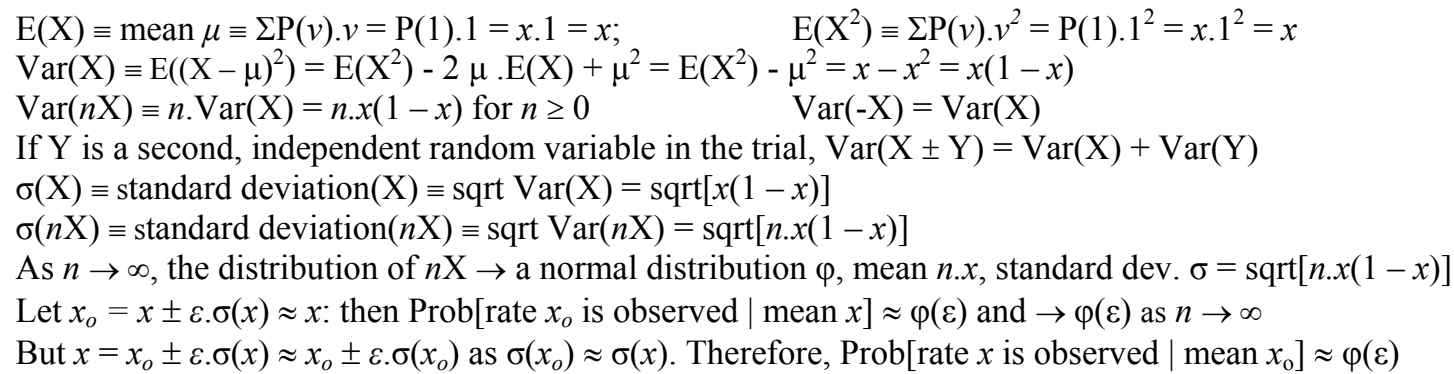

\subsection{Principles of Statistical Inference}

If the initial, neutral, 'know nothing' assumption is made, namely, that any value in the interval $(0,1)$ is equally likely, then the following Bayesian relation holds between the underlying mean $x$ and the observed rate $x_{o}$ :

$\operatorname{Prob}\left[\right.$ mean of $X$ is $\sim x \mid$ rate $x_{o}$ is observed] $\propto \operatorname{Prob}\left[\right.$ rate $x_{o}$ is observed $\mid$ mean of $X$ is $\left.\sim x\right]$

But, if $x_{o} \approx x, \operatorname{Prob}\left[\right.$ rate $x_{o}$ is observed $\mid$ mean of $X$ is $\left.x\right] \approx \operatorname{Prob}\left[\right.$ rate $x$ is observed $\mid$ mean is $x_{o}$ ]. Therefore,

$\operatorname{Prob}\left[\right.$ mean of $X$ is $\sim x \mid$ rate $x_{o}$ is observed] $\rightarrow \operatorname{Prob}\left[\right.$ rate $x$ observed $\mid$ mean is $\sim x_{o}$ ] as $n \rightarrow \infty$.

Therefore, in the limit, the distribution of the random variable $\mathrm{E}(X)$, the mean of the random variable $X$, is the same as the distribution of $X$, assuming the observed rate $x_{o}$ is the mean.

Note that, as $n=3,000$, generously large, $n \cdot x(1-x)>290$ for all frequencies that occurred in the experiment. This is certainly large enough to ensure that:

- $\quad$ observed frequency rates are close to the intrinsic success rates for the random variables,

- the normal distribution $\varphi((\mathrm{X}-\mu) / \sigma)$ is a suitable approximation to the actual probability density functions,

- the theory above may be applied to the experiment, knowing that approximation errors are ignorable.

\subsection{Comparison of Binary and Ternary Models}

Rather than analyse match $M$ results with a ternary win/draw/loss model with random variables $W$ and $D$, Heinz used a binary model with a two-valued random variable $S$ : $\operatorname{Pr}($ win, $\mathrm{S}=1)=s$. Thus, as above:

$$
\mathrm{E}(n S)=n . s \text { and } \operatorname{Var}(n S)=n \cdot s(1-s)
$$

However, if $S$ is a 3-valued random variable with $\operatorname{Pr}(\mathrm{S}=1)=w$ and $\operatorname{Pr}(\operatorname{draw})=d$, then:

$$
\begin{aligned}
\mathrm{E}(\mathrm{S}) & =s=w+d / 2 ; \quad \mathrm{E}\left(\mathrm{S}^{2}\right)=w+d / 4 \\
\operatorname{Var}(n \mathrm{~S}) & =n \cdot \operatorname{Var}(S)=n \cdot\left[\mathrm{E}\left(\mathrm{S}^{2}\right)-(w+d / 2)^{2}\right]=n \cdot\left[(w+d / 4)-(w+d / 2)^{2}\right]= \\
& =n \cdot\left[(s-d / 4)-s^{2}\right]=n \cdot[s(1-s)-d / 4] \leq n \cdot s(1-s), \text { the variance of the equivalent binary model. }
\end{aligned}
$$

Thus, the variance in the ternary model is always less than in the binary model ${ }^{2}$. Heinz' substitution of the binary model was therefore indeed a conservative one, increasing the apparent variances in his experiment.

\footnotetext{
${ }^{2}$ In the extreme, for example, it is 0 rather than 0.25 for $d=1$ and one trial.
} 


\section{ANALYSIS OF THE SELF-PLAY RESULTS}

Heinz' null hypothesis, $S$, is effectively that " $s_{p}$ and therefore $S_{p}$ reduce as $p$ increases". The confidence level with which this statement may be made is the estimated probability of this being demonstrated again by a further match $M_{p}$ of the same length. (see Table 2a for the binary model).

Crucially, Heinz did not use the independence of $S_{i}$ and $S_{j}: \operatorname{Var}\left(S_{i}-S_{j}\right)=\operatorname{Var}\left(S_{i}\right)+\operatorname{Var}\left(S_{j}\right)=\sigma^{2}$ and $S_{i}-S_{j}=k_{i j} \sigma$. The value of $k$ determines the confidence level with which we might say that $S_{i}>S_{j}$.

\begin{tabular}{|c|c|c|c|c|c|c|c|c|c|c|c|c|c|c|}
\hline \multicolumn{6}{|c|}{$\left(S_{i}-S_{j}\right) / \sigma\left(S_{i}-S_{j}\right):$ binary model } & & & \multicolumn{7}{|c|}{ Confidence Levels for the null hypothesis $S$ on scores } \\
\hline $\mathbf{i} \backslash \mathbf{j}$ & 6 & 7 & 8 & 9 & 10 & 11 & 12 & 6 & 7 & 8 & 9 & 10 & 11 & 12 \\
\hline 6 & & -0.934 & 2.271 & 2.619 & 4.629 & 7.095 & 7.941 & & $17.5 \%$ & $98.8 \%$ & $99.6 \%$ & $100.0 \%$ & $100.0 \%$ & $100.0 \%$ \\
\hline 7 & & & 3.206 & 3.554 & 5.566 & 8.036 & 8.884 & & & $99.9 \%$ & $100.0 \%$ & $100.0 \%$ & $100.0 \%$ & $100.0 \%$ \\
\hline 8 & & -— & & 0.348 & 2.355 & 4.813 & 5.656 & & & & $63.6 \%$ & $99.1 \%$ & $100.0 \%$ & $100.0 \%$ \\
\hline 9 & - & - - & & & 2.007 & 4.473 & 5.316 & 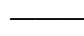 & 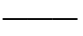 & - & & $97.8 \%$ & $100.0 \%$ & $100.0 \%$ \\
\hline 10 & - - - & - - & 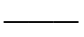 & - & & 2.455 & 3.295 & 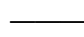 & 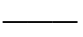 & - & 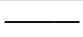 & & $99.3 \%$ & $100.0 \%$ \\
\hline 11 & - & - - & 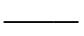 & 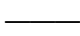 & - & & 0.839 & 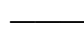 & $\bar{L}$ & - & $\bar{L}$ & $\longrightarrow$ & & $79.9 \%$ \\
\hline
\end{tabular}

Table 2a: $\left(\mathrm{S}_{\mathrm{i}}-\mathrm{S}_{\mathrm{j}}\right)$ in units of $\sigma\left(\mathrm{S}_{\mathrm{i}}-\mathrm{S}_{\mathrm{j}}\right)$ and confidence levels for the null hypothesis: binary model.

The distribution of the random variable $S_{p}$ in the ternary model also converges on a normal distribution by the Central Limit Theorem. As proved above, $\operatorname{Var}\left(\mathrm{S}_{\mathrm{i}}\right)$ and $\operatorname{Var}\left(\mathrm{S}_{\mathrm{i}}-\mathrm{S}_{\mathrm{j}}\right)=\operatorname{Var}\left(\mathrm{S}_{\mathrm{i}}\right)+\operatorname{Var}\left(\mathrm{S}_{\mathrm{j}}\right)$ are lower in this model and Heinz' null hypothesis $S$ may be stated with somewhat more confidence. (see Table $2 \mathrm{~b}$ ).

\begin{tabular}{|c|c|c|c|c|c|c|c|c|c|c|c|c|c|c|}
\hline \multirow[b]{2}{*}{$\mathbf{i} \backslash \mathbf{j}$} & \multicolumn{7}{|c|}{$\left(S_{i}-S_{j}\right) / \sigma\left(S_{i}-S_{j}\right):$ temary model } & \multicolumn{7}{|c|}{ Confidence Levels for the null hypothesis $S$ on scores } \\
\hline & 6 & 7 & 8 & 9 & 10 & 11 & 12 & 6 & 7 & 8 & 9 & 10 & 11 & 12 \\
\hline 6 & & -1.216 & 2.991 & 3.458 & 6.299 & 9.699 & 10.958 & & $11.2 \%$ & $99.9 \%$ & $100.0 \%$ & $100.0 \%$ & $100.0 \%$ & $100.0 \%$ \\
\hline 7 & & & 4.357 & 4.843 & 7.832 & 11.354 & 12.677 & & & $100.0 \%$ & $100.0 \%$ & $100.0 \%$ & $100.0 \%$ & $100.0 \%$ \\
\hline 8 & - & - & & 0.479 & 3.347 & 6.869 & 8.150 & & & & $68.4 \%$ & $100.0 \%$ & $100.0 \%$ & $100.0 \%$ \\
\hline 9 & - - & - - & & & 2.860 & 6.388 & 7.667 & & & - - & & $99.8 \%$ & $100.0 \%$ & $100.0 \%$ \\
\hline 10 & - & - & 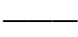 & - & & 3.625 & 4.915 & 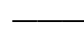 & 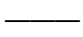 & - & 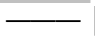 & & $100.0 \%$ & $100.0 \%$ \\
\hline 11 & - & - & $\overline{-}$ & - & - & & 1.256 & 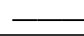 & 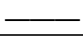 & - & 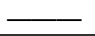 & - & & $89.5 \%$ \\
\hline
\end{tabular}

Table 2b: $\left(\mathrm{S}_{\mathrm{i}}-\mathrm{S}_{\mathrm{j}}\right)$ in units of $\sigma\left(\mathrm{S}_{\mathrm{i}}-\mathrm{S}_{\mathrm{j}}\right)$ and confidence levels for the null hypothesis: ternary model.

Clearly, we can state with $99.9 \%+$ confidence that the winner's score decreases in the two match sequences $\left\{M_{6}, M_{8}, M_{10}, M_{12}\right\}$ and $\left\{M_{7}, M_{9}, M_{11}\right\}$.

The null hypotheses $W$, “ $W_{p}$ reduces as $p$ increases", and $D$, " $D_{p}$ increases as $p$ increases", are suggested by the data: confidence levels have also been calculated for these statements (see Tables 3 and 4). Both $W_{p}$ and $D_{p}$ are binary variables. Curiously, there is no obvious trend in the corresponding binary variable $L_{p}$.

\begin{tabular}{|c|c|c|c|c|c|c|c|c|c|c|c|c|c|c|}
\hline \multicolumn{5}{|c|}{$\left(W_{i}-W_{j}\right) / \sigma\left(W_{i}-W_{j}\right)$} & \multicolumn{10}{|c|}{ Confidence Levels for the null hypothesis $W$ on wins } \\
\hline $\mathbf{i} \backslash \mathbf{j}$ & 6 & 7 & 8 & 9 & 10 & 11 & 12 & 6 & 7 & 8 & 9 & 10 & 11 & 12 \\
\hline 6 & & 1.117 & 5.937 & 6.561 & 11.327 & 14.803 & 16.618 & & $86.8 \%$ & $100.0 \%$ & $100.0 \%$ & $100.0 \%$ & $100.0 \%$ & $100.0 \%$ \\
\hline 7 & & & 4.814 & 5.437 & 10.189 & 13.648 & 15.452 & & & $100.0 \%$ & $100.0 \%$ & $100.0 \%$ & $100.0 \%$ & $100.0 \%$ \\
\hline 8 & - & - - & & 0.620 & 5.331 & 8.738 & 10.508 & & 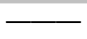 & & $73.2 \%$ & $100.0 \%$ & $100.0 \%$ & $100.0 \%$ \\
\hline 9 & & - - & - & & 4.708 & 8.111 & 9.877 & & 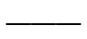 & -- & & $100.0 \%$ & $100.0 \%$ & $100.0 \%$ \\
\hline 10 & - & - - & - & & & 3.382 & 5.131 & & & $-\square$ & 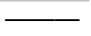 & & $100.0 \%$ & $100.0 \%$ \\
\hline 11 & - & - - & 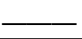 & $\longrightarrow$ & - & & 1.745 & 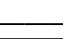 & - & - & $\longrightarrow$ & - & & $95.9 \%$ \\
\hline
\end{tabular}

Table 3: $\left(\mathrm{W}_{\mathrm{i}}-\mathrm{W}_{\mathrm{j}}\right)$ in units of $\sigma\left(\mathrm{W}_{\mathrm{i}}-\mathrm{W}_{\mathrm{j}}\right)$ and confidence levels for the null hypothesis.

Again, the two match sequences $\left\{M_{6}, M_{8}, M_{10}, M_{12}\right\}$ and $\left\{M_{7}, M_{9}, M_{11}\right\}$ demonstrate the null hypothesis with high levels of confidence, as do $\left\{M_{7}, M_{8}\right\}$ and $\left\{M_{9}, M_{10}, M_{11}, M_{12}\right\}$. 


\begin{tabular}{|c|c|c|c|c|c|c|c|c|c|c|c|c|c|c|}
\hline \multicolumn{8}{|c|}{$\left(D_{i}-D_{j}\right) / \sigma\left(D_{i}-D_{j}\right)$} & \multicolumn{7}{|c|}{ Confidence Levels for the null hypothesis $D$ on draws } \\
\hline $\mathbf{i} \backslash \mathbf{j}$ & 6 & 7 & 8 & 9 & 10 & 11 & 12 & 6 & 7 & 8 & 9 & 10 & 11 & 12 \\
\hline 6 & & -4.151 & -8.059 & -8.669 & -14.402 & -16.387 & -18.204 & & $100.0 \%$ & $100.0 \%$ & $100.0 \%$ & $100.0 \%$ & $100.0 \%$ & $100.0 \%$ \\
\hline 7 & & & -3.889 & -4.495 & -10.158 & -12.108 & -13.888 & & & $100.0 \%$ & $100.0 \%$ & $100.0 \%$ & $100.0 \%$ & $100.0 \%$ \\
\hline 8 & & - & & -0.604 & -6.230 & -8.158 & -9.913 & & 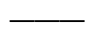 & & $72.7 \%$ & $100.0 \%$ & $100.0 \%$ & $100.0 \%$ \\
\hline 9 & & - - & & & -5.623 & -7.547 & -9.299 & & 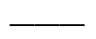 & - & & $100.0 \%$ & $100.0 \%$ & $100.0 \%$ \\
\hline 10 & - - & - - & & & & -1.911 & -3.645 & & 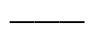 & - & & & $97.2 \%$ & $100.0 \%$ \\
\hline 11 & - - & - - & - & - & - & & -1.732 & 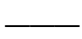 & - & - & 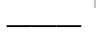 & - & & $95.8 \%$ \\
\hline
\end{tabular}

Table 4: $\left(D_{i}-D_{j}\right)$ in units of $\sigma\left(D_{i}-D_{j}\right)$ and confidence levels for the null hypothesis.

For a third time, the two match sequences $\left\{M_{6}, M_{8}, M_{10}, M_{12}\right\}$ and $\left\{M_{7}, M_{9}, M_{11}\right\}$ demonstrate with high levels of confidence, the null hypothesis that the rate of draws increases with $p$. The sequences $\left\{M_{7}, M_{8}\right\}$ and $\left\{M_{9}\right.$, $\left.M_{10}, M_{11}, M_{12}\right\}$ are equally encouraging.

\section{SUMMARY}

This note has revisited Heinz' comprehensive self-play experiment in chess and re-assessed the significance of his results for the null hypothesis "an increment of search depth yields decreasing returns". It appears that the confidence levels with which this may be stated are better than as suggested in his original paper.

Ancillary null hypotheses, on the decreasing frequency of wins and the increasing frequency of draws, were also suggested by the data and hold with good levels of confidence.

Some open questions that arose during this investigation:

- to what extent are the characteristics of the chosen engine, FRITZ, affecting the experimental results?

- why is there no comparable trend in $l_{p}$, the underlying mean of $L_{p}$ ?

- $\quad$ given a possible stm/sntm position evaluation bias, should $M_{s}$ be compared with $M_{s-2}$ rather than $M_{s-1}$ ?

- $\quad$ does the one ply search-depth advantage initially deliver increasing benefits with depth, c.f. $M_{6}$ and $M_{7}$ ?

- $\quad$ are there other perhaps increasing-return trends in shallow-search matches, e.g., $M_{2}-M_{7}$ ?

- $\quad$ as $p \rightarrow \infty$, does $s_{p}$ decrease to a limit greater, equal to or less than 0.5 ?

The apparently anomalous $M_{6} / M_{7}$ results suggest further investigation at the conveniently shallow end of the experiment. Were Heinz' experimental results here a 'one off' or does the one-ply advantage increasingly overcome random play at small depths of search?

Thanks goes to Ernst Heinz for his comprehensive self-play experiment and results.

\section{REFERENCES}

Feller, W. (1968). An Introduction to Probability Theory and Its Applications. $3^{\text {rd }}$ Edition. J. Wiley and Sons: Series in Probability and Mathematical Statistics. ISBN 0-4712-5708-7.

Heinz, E.A. (2000a). Scalable Search in Computer Chess. Vieweg Verlag. Wiesbaden, esp. p. 178. ISBN 35280-5732-7.

Heinz, E.A. (2000b). A New Self-Play Experiment in Computer Chess. Technical Memo No. 608 (MIT-LCSTM-608). Laboratory or Computer Science, Massachussetts Institute of Technology.

Heinz, E.A. (2001a). New Self-play Results in Computer Chess. Proceedings of the $2^{\text {nd }}$ International Conference on Computers and Games (eds. I. Frank and T.A. Marsland), pp. 267-280. Lecture Notes in Computer Science (eds. G. Goos, J. Harmanis and J. van Leeuwen), Springer-Verlag, Berlin. ISBN 3-54043080-6.

Heinz, E.A. (2001b). Self-play, Deep Search and Diminishing Returns. ICGA Journal, Vol. 24, No. 2, pp. $75-$ 79. ISSN 1389-6911. 